\title{
Health System Research: Development, Designs and Methods
}

\author{
${ }^{1}$ Tulsi Ram Bhandari \\ ${ }^{1}$ Achutha Menon Centre for Health Science Studies, Sree Chitra Tirunal Institute for Medical Sciences and Technology, \\ Trivandrum, Kerala, India
}

\begin{abstract}
Health system research concerns with health system and its results provide the bases to managers, policy makers as well as community people to make evidence based decision. There are different interpretations of what a health system is. In narrow meaning, health system is considered the different levels of the health care services such as central level health care, statel provincial level health care, regional/zonal/district level health care and local level health care. In broad aspect, health system covers different aspects of society such as socio-economic status, culture, religion, education, politics, public sector, private sectors which are the major determinants of social epidemiology. It is also a knowledge generation to improve how societies organise to achieve health goals and contributes to sound, socially relevant and ethically acceptable guidelines for more effective, efficient and sustainable health policies and systems.
\end{abstract}

Key words: Health system research, development, designs, methods, healthcare research

Corresponding address: Tulsi Ram Bhandari, Achutha Menon Centre for Health Science Studies, Sree Chitra Tirunal Institute for Medical Sciences and Technology Trivandrum, Kerala, India.

E-mail: tulsib2004@gmail.com/tulsibhandari@sctimst.ac.in

\section{INTRODUCTION}

Research is a systematic collection, analysis and interpretation of data to answer a certain question or solve a problem. It is embedded in epistemological positions and theoretical framework. It demands a clear statement of the problem and requires clear objectives and a plan. Researchers collect evidence and analyze systematically to answer the original research objectives. ${ }^{1}$ Most of the researchers adopt either qualitative or quantitative methods and somewhere they apply inductive and deductive ways simultaneously. ${ }^{2}$ Now a day social sciences and health system researchers prefer hybridized methods rather than single one.

Health system research is a part of health research. It closely links field evidences and applies its results for the improvement of the health system. Initially, it was known as health service research and the terminology shifted to health system research from 1980s. The health service research focused on problems encountered in government health care facilities. Health system research considers that health depends to a large extent on variables outside the health care and studies the health system as a whole. ${ }^{3-7}$

Most of the health care researches has been carried out in developed countries with well established health services for assuring the quality and cost containment. But there is urgent need for health system research in under developing countries to enhance the entire health system including health care problems. ${ }^{4,8}$

Health System Research is defined as "the multidisciplinary field of scientific investigation that studies how social factors, financing systems, organizational structures and processes, health technologies, and personal behaviours affect access to health care, the quality and cost of health care, and ultimately our health and well-being. Its research domains are individuals, families, organizations, institutions, communities and populations." 9

Health system research is a knowledge generation to improve how societies organise themselves to achieve health goals, including how they plan, manage and finance activities to improve health, as well as the roles, perspectives and interests of different actors in this effort. It contributes to sound, socially relevant and ethically acceptable guidelines for more effective, efficient and sustainable health policies and systems.

\section{Development}

Health system research is a new branch of health research with very short history. Here, we discuss the entire historical development of health system research briefly. ${ }^{4-5}$

\section{Health Services Research (1967-1970)}

In 1967, at first time World Health Organization introduced Research in Epidemiology and Communication Science. The other major events during this period were-

- Establishment of Division of Research in Epidemiology and Communication Science for health care services research in 1967.

- In 1972, restructured Division of Research in Epidemiology and Communication Science into Division of Strengthening Health Services and transferred health services research responsibilities. 
- In 1978, formed Global Advisory Committee on Medical Research and Sub-committee on health services research for articulating the growing awareness of the role of health system research with the goal Health for All -2000 and implementing the Primary Health Care approach successfully.

- In 1980, as per the recommendation of Health Services Research Sub-Committee, World Health Organization had recognized Health Services Research as an important primary area and set up Health System Research.

\section{Health Systems Research (1980-1990)}

World Health Organization considered the Health System Research as an organization for health system research and given following mandate for further work-

- Promotion, coordination and information exchange in the practice of health system research,

- Strengthening of national capabilities for health system research training and development, and

- Support to substantive research in health system priority areas.

From Technical Discussions to Cohered (1990-1993)

- In 1990, Technical Discussion during the Forty-Third World Health Assembly recognized and accepted health system research and took as an essential tool of health development.

- Under the overall theme of "the role of health research in the strategy for health for all by the year 2000", the technical discussions finalized four major themes in health research.

- Health systems research,

- Research capability strengthening,

- Nutrition research and

- $\quad$ Science, research and health care.

Ad-hoc Committee, Global Forum and Alliance (1994 and onwards)

- In mid 1990's, Health System Research and Development integrated with the Division for Strengthening of Health Services.

- Ad-hoc Committee submitted its report with one of the first recommendation made "Health System Development: Strategies for Future".

- In 2000, launched Health Policy and System Research under the umbrella of the Global Forum for Research with the objectives-

- Stimulate the new generation, synthesis of knowledge and encompassing evidence.

- Facilitate to development of capacity for the generation, dissemination and use of knowledge among researchers, policy makers and other stakeholders.

- Promote the dissemination and use of knowledge to improve the performance of health systems.

- In 2002, public health system research interest group (PHSR-IG) initiated a new sub area Public Health System Research under the umbrella of Health System Research.

\section{OBJECTIVE}

Health system research provides relevant and required information at all levels health mangers, other stakeholders and community members whenever they need to make decision and facing problem in their work. ${ }^{3}$

\section{Need and Importance}

Nowadays, there is a broad consensus that health system research is important, but little general agreement as to what it actually is. Even though it remains the realm of research as well as health research because it adopts methods that yield- ${ }^{4}$

Reducibility: Solutions apply to similar problems and conditions elsewhere would produce similar results.

The ability to identify the key elements of a problem: The characteristics that make research approaches from one setting applied in other setting.

An understanding of causation: Relationship between actions and impact can be organized in concepts and theories that may be usefully applied to the prevention or modification of health problem generally. The fundamental principle of health system research is that the questions of studies should be relevant to the everyday concerns of policy-makers, administers or anyone responsible for health care.

\section{Scopes}

The most important single issues in health system research is to learn how to ask the right questions, with the aims of improving understanding of the structure and functioning of the whole health system and indentifying the particular problems in specific situations. Health system research covers complex bio-physical and socio-cultural environmental factors such as geography, socio-economic, culture, politics, demography, etc. The health system research mainly focuses on- ${ }^{3}$

- Health policy and planning in relation to needs, resources, strengthening and changing existing interventions.

- Community perceived and health professionally determined health needs considering mortality, morbidity and disability.

- Health system research concerns for human resources and financial resources including taxes, user fees, insurance, contributions, community resources and support, etc.

- Adequacy, coverage, acceptability, affordability, equitability of intervention programmes.

\section{Research Process}

Health System Research process consists of series of actions or steps necessary to effectively carry out in research. There 
is no consensus among the researchers on research process even if the common steps are in practice as follows (in Fig.1) $-1,3,10$

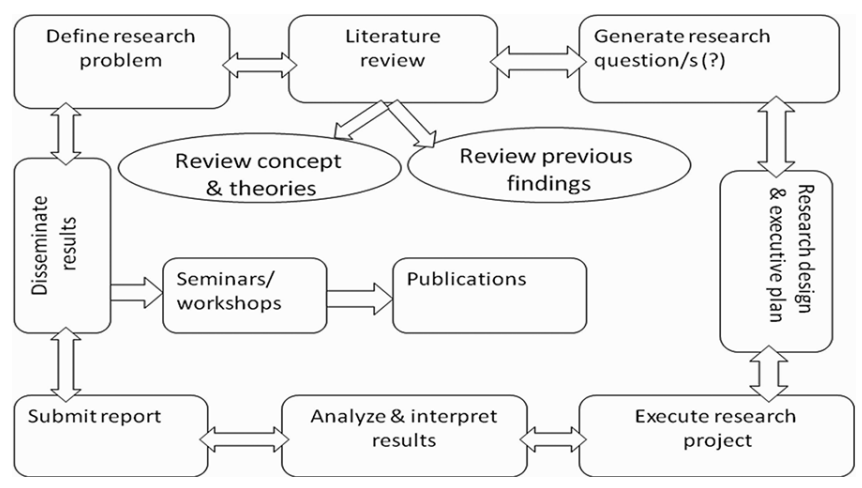

Fig. 1 Research Steps/Process Flowchart

\section{Some Closed Researches With Health System Research}

Either before or after the conception of Health System Research, Health Services Research -1972, Health Policy and Systems Research - 2000, and Public Health System Research - 2002 are functioning in the health care system very closely with health system research. To some extent, they create confusion in health system research. ${ }^{11}$ This paper focuses to clarify the confusion and define each of them separately.

The health service research is concerned as much as narrow study rather than health system research. Most of the health service researches were carried out in developed countries with well-established health services. The focus has been on improving the functioning of hospitals with concerning quality assurance and cost containment. Gradually, health service researches have been replaced by health system research from late 1970 's. ${ }^{4}$

The health policy and system research is a field that seeks to understand and improve how societies organize themselves in achieving collective health goals and how different actors interact in the policy and implementation processes to contribute to policy outcomes. By nature, it is interdisciplinary, a blend of economics, sociology, anthropology, political science, public health and epidemiology that together draw a comprehensive picture of how health systems respond and adapt to health policies, and how health policies can shape and be shaped by health systems and the broader determinants of health. ${ }^{12-13}$

Similarly, Public health system research is defined as a field of study that examines the organization, financing, and delivery of public health services within communities and the impact of these services on population health. It has emerged as a "sister discipline" to health system research; both fields share a related set of research questions, have a common base of methods, and often rely on similar or related data sources to develop meaningful research on population health. ${ }^{14}$
Somewhere, there found public health services and system research. It has not any remarkable differences from public health system research.

\section{DESIGNS AND METHODS}

Health system research is more inclusive in its approaches, and methods are being barrowed from many disciplines. Since it is still growing, it would be bias and unproductive to be restrictive in specifying which methods should be used. It is a broad area of research which covers different aspects of health care system such as health policy, health service utilization, community participation, health service demand and supply trends, etc. ${ }^{15-16}$

In health system research researchers can solve their research questions by gathering different evidences from health facilities and service users. They can collect qualitative and quantitative information for drawing the inference sharply. ${ }^{2}$ ${ }^{15}$ The most used research designs, methods/techniques and tools are discussed here accordingly.

Designs: A study design is a specific plan or protocol for conducting the study, which allows the investigator to translate the conceptual hypothesis into an operational one. ${ }^{17,18}$ We can classify health system study designs mainly into two groups: Non-interventional and interventional. The most common health system research designs are as follows-

\section{Non- interventional studies}

$\rightarrow$ Exploratory studies: piloting studies, small scale comparative studies.

$\rightarrow$ Descriptive studies: case studies, survey, census

$\rightarrow$ Comparative/ analytical studies: cross-sectional comparative studies, case-control studies, cohort studies.

$\rightarrow$ Evaluation and System review: Cost analysis, document analysis, content analysis

$\rightarrow$ Meta-analysis

$\rightarrow$ Systematic review

Intervention studies

$\rightarrow$ Experimental studies

$\rightarrow$ Quasi-experimental studies

$\rightarrow$ Before -after (pretest - posttest) experimental studies

Methods: A systematic process of achieving certain ends with accuracy and efficiency, in an ordered sequence of fixed steps. The often used research methods/techniques and tools in health system research are as follows- ${ }^{2}, 15,16,19$

\section{ETHICAL ISSUES}

Ethical issues are lifting day-by-day in health system research at individual, organizational and government levels. The online access of research results and use of the technological innovation in research activities are advantages for health system research, even though these all are not free from the ethical issues. The most occurred ethical issues are respect of participants, taking ethical approval and informed consent, 
distribution of benefits and prevention of risks and maintaining the individual autonomy of participants. Dissemination and publication of results, implement the research protocol with unique human nature, sharing of interventions between case and control groups are other potential ethical issues in health system research. ${ }^{20-22}$

Table 1. Methods and Tools of Health System Research

\begin{tabular}{|c|c|c|}
\hline \multicolumn{2}{|l|}{ Methods } & \multirow{2}{*}{\begin{tabular}{|l|}
\multicolumn{1}{|c|}{ Tools } \\
$\begin{array}{l}\text { Structured } \\
\text { interview schedule/ } \\
\text { questionnaire }\end{array}$
\end{tabular}} \\
\hline \multirow{12}{*}{ Quantitative } & $\begin{array}{l}\text { Survey/ census: } \\
\text { structured Interview/ } \\
\text { self administered } \\
\text { questionnaire } \\
\end{array}$ & \\
\hline & $\begin{array}{l}\text { Service statistics/record } \\
\text { review }\end{array}$ & Checklist \\
\hline & $\begin{array}{l}\text { Systematic/extensive } \\
\text { review }\end{array}$ & Combined tools \\
\hline & Observation & checklist \\
\hline & $\begin{array}{l}\text { Administering } \\
\text { questionnaire }\end{array}$ & Questionnaire \\
\hline & System analysis/review & Combined tools \\
\hline & $\begin{array}{l}\text { Secondary data use/ } \\
\text { analysis }\end{array}$ & Statistical software \\
\hline & Content analysis & Combined tools \\
\hline & Policy analysis & Combined tools \\
\hline & Meta-analysis & Statistical software \\
\hline & $\begin{array}{l}\text { Social Network } \\
\text { Analysis(SNA) } \\
\end{array}$ & Combined tools \\
\hline & $\begin{array}{l}\text { Mapping(Process \& } \\
\text { Service) }\end{array}$ & $\begin{array}{l}\text { With GIS map/ sketch } \\
\text { map }\end{array}$ \\
\hline \multirow{5}{*}{ Qualitative } & Case studies & $\begin{array}{l}\text { Guideline/structured } \\
\text { format/conceptual } \\
\text { framework } \\
\end{array}$ \\
\hline & $\begin{array}{l}\text { Focus Group Discussion } \\
\text { (FGD) }\end{array}$ & Guideline \\
\hline & In-depth interview & Guideline \\
\hline & Participatory observation & Checklist/daily diary \\
\hline & Cognitive mapping & With GIS map/sketch map \\
\hline \multirow[t]{2}{*}{$\begin{array}{l}\text { Mixed methods } \\
\text { (Triangulation) }\end{array}$} & $\begin{array}{l}\text { E.g. FGD+ In-depth } \\
\text { interview }+ \text { structured } \\
\text { interview }\end{array}$ & $\begin{array}{l}\text { Guidelines }+ \\
\text { Interview schedule }\end{array}$ \\
\hline & Projective techniques & $\begin{array}{l}\text { Combined with } \\
\text { other methods } \\
\text { (FGD, questionnaire, } \\
\text { interview guidelines }\end{array}$ \\
\hline
\end{tabular}

\section{ACKNOWLEDGEMENT}

I wish to acknowledge to all writers, editors and publishers of the reviewed literatures. Similarly, I express my gratefulness to Prof. V. Raman Kutty and Doctorial Advisory Committee members, Achutha Menon Centre for Health Science Studies, Sree Chitra Tirunal Institute for Medical Sciences and Technology, Trivandrum, Kerala, India for their guidance and consistent support to prepare this paper and search the literature.

\section{REFERENCES}

1. Kothari CR. Research methodology methods \& techniques. New Delhi: New Age International (P) Ltd. 2004.

2. Hesse-Biber SN, Leavy P. Handbook of emergent methods. The Guilford Press; 2010 [cited 2012 Sep 14]. Available from: URL :http://books.google.co.in/books

\section{LIMITATION}

Health system research often concerns with human being, their activities and interest. Researcher should respect of human subject and address their demand and interest which is challenging task in the health system research. Equal participation and randomization of the study subject, high turnover due to retirement, transfer and change the job, make agreement between organization policy and findings of the research, control the cost and proper distribution of the benefits, implementation of results with scare resources, vested interest and influence of donors, hard to get access and permission for publication and dissemination of results from health organizations are the common limitations of health system research. ${ }^{12,22,23}$

\section{CONFLICT OF INTEREST}

Ethical integrity in the conduct of health care researchers is essential for maintaining the public trust and support of such activities. A conflict of interest occurs when vested interest influences professional decisions regarding healthcare, education, or research. It is important to recognize conflicts of interest when a significant financial interest of conflicts with human subject research, the investigator is prohibited for continuing the research. If the conflict does not affect human subjects, in some instances a conflict of interest management plan can be developed that allows continued the research. The common interest of conflicts are disagreement among researchers, financial issues and quality, disseminating and publishing the results, maintaining the distance and relationship with participants, government's regulations, policies, programs, interest and so on which are mainly classified into two broad groups: financial and nonfinancial. ${ }^{24-27}$

\section{CONCLUSION}

Health System Research is a new discipline of research as well as health research. It concerns with health system and its results provide bases to managers, policy makers as well as community people to make evidence based decision. Health services research, health policy and system research and public health system research are very closer to the health system research, even though they create a lot of confusion in health system research. Often, health system research has been influenced by global politics and investments rather than its own philosophy. 
3. Varkevisser CM, Pathmanathan I, Brownlee AT. Designing and conducting health systems research projects: Proposal development and fieldwork. Kit Publishers; 2003 [cited 2012 Sep 14]. Available from: URL: http://books.google.co.in/ books

4. Taylor CE, Salud OM. The uses of health systems research. WHO; 1984 [cited 2012 Sep 14]. Available from: URL: http:// whqlibdoc.who.int/php/WHO_PHP_78.pdf

5. Nuyens Y. Health system research and world health organization: facts, events, issues, perspectives and documents. Geneva, Switzerland: World Health Organization; 2000.

6. Sauerborn R, Nitayarumphong S, Gerhardus A. Strategies to enhance the use of health systems research for health sector reform. Tropical Medicine \& International Health 1999; 4:827-35.

7. Hanney SR, Gonzalez-Block MA, Buxton MJ, Kogan M. The utilisation of health research in policy-making: concepts, examples and methods of assessment. Health Research Policy and Systems 2003; 1:2.

8. El Turabi A, Hallsworth M, Ling T, Grant J. A novel performance monitoring framework for health research systems: experiences of the National Institute for Health Research in England. Health Research Policy and Systems 2011;9:13.

9. Academic Health. A Needs Assessment for Data and Methods in Public Health Systems Research. [cited 2012 Oct 13]. Available from: URL: http://www.academyhealth.org/files/interestgroups/phsr/FinalPhsrNAjan2010.pdf

10. Omi S. Health Research Methodology a Guide for Training in Research Methods. World Health Organization Regional Office for the Western Pacific; 2001. [cited 2012 Sep 14]. Available from: URL: http://eprints.undip.ac.id/1114/

11. Mills A. Health policy and systems research: defining the terrain; identifying the methods. Health policy and planning 2012; 27:1-7.

12. Reader AM. Health Policy and Systems Research. 2012 [cited 2012 Oct 14]; Available from URL: http://www.who.int/ entity/alliance-hpsr/resources/alliancehpsr

13. Gonzalez-Block MA. Health policy and systems research agendas in developing countries. Health Research Policy and Systems 2004; 2:6.

14. McPake B, Blaauw D, Sheaff R. Recognising patterns: health systems research beyond controlled trials. Meeting of the London School of Hygiene and Tropical Medicine Health Systems Discussion Group. 2006. [cited 2012 Oct 13]. Available from: URL http://www.dfid.gov.uk/r4d/PDF/Outputs/HealthSysDev_KP/recognising_patterns_web_version.pdf

15. Remme JHF, Adam T, Becerra-Posada FD, Arcangues C, Devlin M, Gardner C, et al. Defining Research to Improve Health Systems. PLoS Med. 2010; 7:e1001000.

16. Bowling A. Research methods in health. Open University Press; 2009 [cited 2012 Oct 13]. Available from: http://books. google.co.in/books

17. Study Design 101 [Internet]. [cited 2012 Sep 19]. Available from: http://www.gwumc.edu/library/tutorials/studydesign101/

18. Patsopoulos NA. Relative citation impact of various study designs in the health sciences. JAMA. 2005; 293:2362-6.

19. Blanchet K, James P. How to do (or not to do) ... a social network analysis in health systems research. Health Policy Plan 2012; 27:438-46.

20. Buse K. Addressing the theoretical, practical and ethical challenges inherent in prospective health policy analysis. Health policy and planning 2008; 23:351-60.

21. Ménard J-F. A "Nudge" for Public Health Ethics: Libertarian Paternalism as a Framework for Ethical Analysis of Public Health Interventions? Public Health Ethics 2010; 3:229-38.

22. Eysenbach G, Till JE. Ethical issues in qualitative research on internet communities. BMJ. 2001; 323:1103-5.

23. Zydziunaite V, Suominen T, AAstedt-Kurki P, Lepaitė D. Ethical dilemmas concerning decision-making within health care leadership: a systematic literature review. Medicina (Kaunas) 2010; 46:595-603.

24. Fiack K, Knapp K, Lee D. Competing interests in healthcare: a conflict of quality. Part II: regulations, transparency, and policy implications. J Med Pract Manage. 2012 Aug; 28:13-7.

25. Shekelle PGPG, Ruelaz AA, Miake-Lye IMIM, Beroes JMJM, Newberry SS. Maintaining Research Integrity: A Systematic Review of the Role of the Institutional Review Board in Managing Conflict of Interest. Washington (DC): Department of Veterans Affairs; 2012 [cited 2012 Sep 14]. Available from: http://www.ncbi.nlm.nih.gov/pubmed/22787689

26. West Los Angeles VA, Ruelaz A, Miake-Lye IM, Beroes JM, Newberry S. Maintaining Research Integrity: A Systematic Review of the Role of the Institutional Review Board in Managing Conflict of Interest. 2012 [cited 2012 Oct 14]; Available from: http://www.hsrd.research.va.gov/publications/esp/research_integrity.pdf

27. Field MJ. Practice I of M (U S) C on C of I in MR, Education and Conflict of Interest in Medical Research, Education, and Practice. US: National Academies Press; 2009 